\title{
A HISTORIOGRAFIA DA EDUCAÇÃO BRASILEIRA, O PERÍODO POMBALINO E O DIRETÓRIO DE 1757.
}

\author{
Alberto Damasceno ${ }^{1}$
}

\section{RESUMO}

No governo de Francisco Xavier de Mendonça Furtado, $19^{\circ}$ (décimo-nono) Governador e Capitão-general do Estado do Grão-Pará e Maranhão entre os anos de 1751 e 1759, dá-se início a um amplo processo de transformações que culminaria, dentre outros acontecimentos, com o surgimento - pela primeira vez na América portuguesa (território composto pelo Estado do Grão-Pará e Maranhão e pelo Estado do Brasil) — de escolas estatais que viriam a substituir o sistema jesuítico de educação elementar, antes mesmo da reforma do ensino de Carvalho e Melo deflagrada a partir de Lisboa. O instrumento legal que demarca este período é o Directório que se deve observar nas povoações dos índios do Pará e Maranhão enquanto Sua Majestade não mandar o contrário ou, simplesmente, "Diretório" de 1757, editado em 3 de maio de 1757, confirmado pelo Alvará Régio de 17 de agosto de 1758 e abolido pela Carta Régia de 12 de maio de 1798. O "Diretório" pode ser considerado o mais importante documento de política educacional da história da América portuguesa naquele período. Infelizmente ainda é pouco conhecido e estudado como tal.

Palavras-chave: História da Educação; Pombal; Diretório.

\section{THE HISTORIOGRAPHY OF BRAZILIAN EDUCATION, AND DIRECTORY THE POMBALINO PERIOD 1757}

\begin{abstract}
In the government of Francisco Xavier de Mendonça Furtado, 19th (nineteenth) Governor and Captain-General of the State of Grão-Pará and Maranhão between the years 1751 and 1759 , is initiated a broad process of transformation that would culminate, among other events, with the emergence - the first time in Portuguese America (territory comprising the State of Grão-Pará and Maranhão State and Brazil) - the state schools that would replace the Jesuit system of elementary education, even before the reform teaching Carvalho e Melo triggered from Lisbon. The legal instrument that marks this period is the directory that should be observed in the villages of the Indians of Pará and Maranhão while His Majesty does not send or otherwise, simply, "Directory", 1757, published on May 3, 1757, confirmed by the Permit regal August 17, 1758 and abolished by the royal Charter of 12 May 1798. The "Directory" can be considered the most important policy document of the educational history of Portuguese America in that period. Unfortunately, there is little known and studied as such.
\end{abstract}

Keywords: History of Education; Pombal; Directory 


\section{Introdução}

Visando contribuir com o debate sobre a produção historiográfica referente à educação brasileira Miriam Warde (1984, p.1) fez um,

[...] levantamento, através de diferentes fontes, demonstrando menos preocupação com uma representatividade quantitativa e mais interesse em balancear as temáticas, os períodos mais estudados e as referências teóricas nas quais os trabalhos têm se apoiado.

Postulando que mais de oitenta por cento dos estudos referem-se à etapa republicana a autora assinala que os estudos relativos à Colônia, abordam o caráter elitista da educação jesuíta e depois as modificações introduzidas na educação anterior.(WARDE 1984, p.2)

Eliane Marta Teixeira Lopes também alerta para o fato de que poucos estudos dedicam-se ao Brasil colônia e aponta algumas questões referentes a novos objetos.

Área que se beneficiou ainda menos dos avanços nas pesquisas históricas é a da educação no período colonial. Poucos e antigos são os estudos a ela referentes, limitados, em sua maioria, à ação dos jesuitas. Outras práticas — e não apenas a da educação formal - existiram, e delas é importante que se saiba. Para isso é preciso que se busquem novas fontes e se releiam as antigas (mesmo aquelas que não tratam especificamente da educação) sob um novo ponto de vista. (LOPES, 1989, p. 65-66).

Esse trabalho inscreve-se na tendência classificada por Warde $(1984$, p.1) como aquela onde o objeto em exame determina a periodização e, portanto, a postulação de diferentes marcos históricos. Ele é resultante de uma pesquisa bibliográfica e documental, dedicada a analisar e sistematizar elementos que contribuíssem para uma reconstrução das origens da educação estatal na América portuguesa, situadas no período colonial pombalino. Entretanto, a consecução deste objetivo não ocorreu sem a superação de alguns obstáculos importantes, pois como era de se esperar, deparei-me com a dificuldade em acessar fontes para as investigações. Saviani já alertava para isso ao sugerir a historiadores da educação latino-americanos

[...] para que se possa fazer comparações e elaborar sínteses, é necessário dispor de material suficientemente ordenado, isto é, analiticamente organizado. Isto implica que em cada um dos nossos países sejam organizados núcleos que se dediquem sistematicamente e de forma continuada ao levantamento, análise e ordenação das fontes disponíveis. Com isso seria possível a produção sistemática de estudos consistentes tratando de temas/ períodos específicos de nossa história educacional, sobre cuja base seriam elaboradas sínteses de longo alcance que resultariam inviáveis ou demandariam um tempo excessivo sem esses trabalhos preliminares que poderíamos chamar de "monografias de base". (SAVIANI, 1996, 13).

Um problema preliminar com o qual me defrontei foi o do difícil acesso a fontes manipuláveis. Busquei documentos — oficiais e oficiosos - e estudos sobre a época, fazendo um levantamento de fontes primárias e secundárias (documentais e bibliográficas), manuscritas e/ou impressas. Analisei Leis, Correspondências, Relatórios e Falas dos Governadores e Capitães-Mores, entre outros. Algumas (e poucas) dessas fontes encontrei- 
as na Biblioteca Pública do Estado; no Arquivo Público; nas Bibliotecas do Grêmio Literário Português, da Universidade Federal do Pará e do Núcleo de Altos Estudos Amazônicos - NAEA (vinculado à UFPA) e do Instituto Histórico e Geográfico do Pará. No Rio de Janeiro acessei importantes fontes no Real Gabinete Português de Leitura, no Instituto Histórico e Geográfico Brasileiro e na Biblioteca Nacional. Conheci obras de teor oficialesco ou portadoras de avaliações emotivas, empreendidas no calor dos acontecimentos, que corroboram a complexidade daqueles tempos e suscitam uma forte polêmica a respeito do Marquês de Pombal, seja como estadista insuperável, seja como "encarnação do mal".

No que tange às fontes secundárias, um dos problemas enfrentados foi a grave lacuna existente em relação ao período conhecido por "pombalino", imediatamente consequente ao período "jesuítico". Quando dediquei-me a analisar um conjunto de obras significativas sobre a história da educação no Brasil, muito pouca coisa era dita ou mencionada na bibliografia brasileira.

Concordando com Jorge Nagle (1984, p.29) quanto à importância de,

[...] estabelecer determinados modos de articulação entre os vários enfoques, a fim de enriquecer o estudo, e de tal forma que cada um deles, adequadamente situado, proporcione o aparecimento de trabalhos em que se associam os múltiplos dados ou elementos que interessam à análise do processo educativo.

E para desfrutar de uma visão mais acurada desta dificuldade, procurei classificar e destacar algumas obras (as mais conhecidas no Brasil) que se referem ao tema, buscando fazer um breve levantamento bibliográfico sobre o assunto ${ }^{2}$

O que posso dizer após esta revisão é que, no geral, os títulos de História da Educação no Brasil dão pouca importância à fase conhecida por pombalina.

Em que pese o fato de serem numerosas as referências, a grande maioria dos livros, ou dedica apenas alguns poucos parágrafos ou páginas ou, até mesmo, omite-se em relação à essa fase da educação no Brasil. As exceções existem apenas no caso de alguns trabalhos mais específicos, voltados para o estudo mais focalizado do tema como é o caso da dissertação de Sulamita Castro Azevedo e Silva, "A Reforma Pombalina e a tecnologia educacional"; da tese de Ana Maria Moura Lins (1992), "A burguesia em disfarce: a defesa da ignorância versus as lições do capital"; e dos livros de Laerte Ramos de Carvalho, "As reformas pombalinas da instrução pública" e de Antonio Alberto Banha de Andrade, "A reforma pombalina dos estudos secundários no Brasil", sendo este último, o único que aborda os acontecimentos de 1757 no Grão-Pará.

Trabalhos mais recentes, a exemplo do primeiro volume da coleção "História da vida privada no Brasil: cotidiano e vida privada na América portuguesa" já destacam, com a devida importância, tal acontecimento:

Na Segunda metade do século XVIII, sob Pombal, a Coroa começou a desenvolver uma política de língua, impondo o uso do português e priorizando o ensino da gramática portuguesa. No Grão-Pará e Maranhão, área em que esta política foi mais incisiva, procurou-se difundir o português para legitimar a posse da terra e, inversamente, coibir o uso do nheengatu, visto como um obstáculo e, principalmente, temido como meio de controle dos índios pêlos missionários. Renomearam-se as aldeias indígenas com nomes de localidades portuguesas (Santarém e Soure, por exemplo), proibiu-se o uso de outra língua que não o português e incentivou-se o ensino deste, primeiro, por escolas locais e, 
depois, por seminários em que os alunos viviam sob internato. Os êxitos, porém, foram restritos. (SOUZA, 1997-A, p.340-341).

\title{
A Amazônia na $2^{\mathrm{a}}$ metade do século XVIII e a educação estatal
}

Em um estudo sobre o teatro no Grão-Pará o historiador paraense Vicente Salles demonstra inequívoca admiração pelas medidas do consulado pombalino no Grão-Pará:

\begin{abstract}
Não obstante os grandes recursos extraídos das colônias para a reconstrução de Lisboa, destruída pelo terremoto de 1755, a administração pombalina deixou marcas da consolidação do domínio português no extremo norte e na modernização de Belém, capital do Grão-Pará.

O reinado de D. José está destinado a concluir, por ação eficiente de seu ministro, o trabalho de integração da Amazônia no espaço político do império português na América. Ele também promoveu profundas transformações sociais e econômicas. A importação do escravo negro se tornou regular, mediante o monopólio do tráfico dado à Companhia Geral de Comércio. A imigração portuguesa, principalmente de famílias açorianas, mais constante. Habitantes do Mazagão africano se transportaram para o Mazagão amazônico. A mestiçagem foi estimulada, em especial com os indígenas. Belém, sede do governo, tornou-se uma das principais cidades do império lusitano. Alguns músicos e poetas tornaram-se conhecidos. O bispado paraense mostrou força política com a expulsão dos missionários insubmissos, em especial os jesuítas, e a devassa do Santo Ofício da Inquisição. O bispo execitor daquelas medidas, D. Frei Miguel de Bulhões e Souza, chegou a exercer longa interinidade na governança do Grão-Pará, (...). Combateu-se o uso da língua geral pela obrigatoriedade do ensino da língua portuguesa. Surgiram as primeiras notabilidades nas letras, na religião e na política. Formou-se afinal núcleo artístico capaz de produzir alguns efeitos. (SALLES, 1994, p. 8-9).
\end{abstract}

Em que pese a existência de um certo tom de aprovação às medidas adotadas pelo governo de D. José I na Amazônia, e ressaltando que o ângulo adotado pelo pesquisador prioriza as preocupações com a criação de uma arte (em especial de um teatro) lusoparaense, é patente a realidade de transformações por que passava esta grande região da América lusa. Quer nos âmbitos político, administrativo e econômico, quer no âmbito educacional, a segunda metade do século XVIII representou para o império lusoamericano, em especial para o Estado do Grão-Pará, um período de profunda efervescência e desenvolvimento. ${ }^{3}$

Com a posse de D. José I dá-se a ascensão de Sebastião José de Carvalho e Melo (então Conde de Oeiras, futuramente Marquês de Pombal) ao governo português. A partir deste momento, deflagra-se uma série de acontecimentos diretamente ligados à vida paraense. Já em 1751 o Estado do Maranhão e Grão-Pará, com sede em São Luiz passa a chamar-se Estado do Grão-Pará e Maranhão, com sede em Belém.

Naquele mesmo instante é nomeado como seu governador, Francisco Xavier de Mendonça Furtado, meio-irmão de Carvalho de Melo, que sucede a Francisco Pedro de Mendonça Gurjão. ${ }^{4}$

Em 1755 é criada a Companhia Geral do Grão-Pará e Maranhão, com sede em 
Lisboa, cujo objetivo era fomentar o desenvolvimento econômico da região.

Um ano depois, realiza-se em Lisboa o julgamento de dois moradores do Grão-Pará (Isabel Maria e Adrião Faria) pelo Santo Ofício da Inquisição. De 1763 a 1769 é o próprio Santo Ofício que realiza uma visitação à Belém.

Cerca de dois anos após a criação da Companhia Geral, Mendonça Furtado extingue o Regimento das Missões e estabelece o "Diretório" substituindo a administração dos religiosos por leigos nos aldeamentos. Em Alvará régio de 1758 dá-se sua confirmação.

Em 1759, após diversos conflitos com a Coroa e com o governo do Estado os Jesuítas são expulsos definitivamente do Grão-Pará e Maranhão, assim como, de todo o reino português.

É neste emaranhado de acontecimentos que se dá um fato importantíssimo para a história da educação luso-brasileira, qual seja, o surgimento das primeiras escolas sob direção não-religiosa no território hoje denominado Brasil.

Não é fato recôndito que os jesuítas, assim como outras ordens religiosas, recebiam "favores oficiais" da Coroa portuguesa ${ }^{5}$. Avellar (1983, p. 180) nos informa que no reinado de D. João V, em 1734, a sociedade de Jesus recebia uma dotação de um milhão de réis para o colégio do Rio de Janeiro e de 300 mil réis para o do Maranhão.

Em que pese o fato das atividades jesuíticas serem financiadas pela Coroa, dos jesuítas serem considerados seus "funcionários" e do Estado português "terceirizar" suas ações de colonização através da Companhia de Jesus —, o que pode caracterizar a tarefa jesuítica como de natureza "estatal”, não se pode negar o fato de que o Diretório inaugura um novo tipo de relação estatal. Com essa nova determinação não se trata mais de "terceirização" das atividades educacionais (para tomar o exemplo que nos interessa), mas de uma ação direta. É o Estado mesmo que assume a lida instrucional como agente privilegiado do processo.

Em outras palavras, se é verdade que havia uma íntima relação entre a Companhia de Jesus e a Coroa no que tange às atividades colonizadoras e que aquela tinha suas ações avalizadas pelo Estado português - o que pode caracterizá-las como estatais — também é verdade que o que se passou na Amazônia, em meados do século XVIII, foi uma ruptura radical e inconciliável entre o Estado (representado pelo irmão do Primeiro Ministro) e os jesuítas.

\begin{abstract}
A ação antijesuítica na Amazônia foi ditada por ponderáveis razões (ás vezes com prejuízo da ética política) de ação administrativa. Era a unicidade administrativa que se buscava. Queria ainda o governo a integração econômica do silvícola, pela participação no trabalho da comunidade maior - a colônia —, em vez de confiná-lo na comunidade menor - a missão. (AVELLAR, 1983, p.21).
\end{abstract}

Deste modo, o modelo educacional que substituiu o jesuítico na América portuguesa, mais precisamente na Amazônia do século XVIII, era tendencialmente secular e estatal, assim caracterizado porque o mesmo surge a partir de um documento com conteúdo inédito na história dos Estados portugueses na América, e até mesmo de todo o reino, como comprova o próprio Alvará Régio que o autoriza. Por outro lado, tal acontecimento dá-se em um novo contexto histórico, no âmbito de um processo de separação entre Estado e Igreja em andamento na Europa, que adotou características próprias e peculiares em Portugal. 
No momento da expedição das Instruções a Mendonça Furtado, porém, a ação antijesuítica não era causa em si, pelo mero antijesuitismo. Foi simples efeito, mais tarde, de uma política administrativa laicizante e de supressão de privilégios, voltada para a extinção do regime das Missões, tanto que duas Instruções Secretas ao mesmo governador lhe determinaram regular as terras das missões e visitá-las em correição "sem embargo de qualquer privilégio". (AVELLAR, 1983, p. 22).

Kenneth Maxwell $(1996,104)$ concorda com este argumento quando trata da reforma educacional de Carvalho e Melo:

Assim como muitas das medidas de Pombal, os experimentos iniciais ocorreram no Brasil. Em 1758 o irmão de Pombal [Mendonça Furtado] introduziu o sistema diretivo para substituir a administração secular dos jesuítas ali onde o controle jesuítico sobre as aldeias indígenas havia sido abolido pelos decretos reais em 7 de junho de 1755. (grifo meu).

Andrade (1978, p.5) também concorda com o caráter original do fato amazônico quando fala da primeira fase da reforma pombalina do ensino no Brasil:

Naquela primeira fase, o ensino dos índios restringe-se à instrução elementar de ler e escrever, tomando-se no Norte e Nordeste a iniciativa de elaborar textos básicos de orientação, como o Diretório e a Cartilha-catecismo [...]. (grifo meu).

Outro lado da questão é abordado por Hélio Avellar (1983, p. 161):

A educação no Brasil colonial pode ser dividida em duas fases: antes e depois de 1760. A primeira foi eminentemente jesuítica, embora seja discutível o aparente caráter exclusivamente privado da escola, face à união entre o Estado e a Igreja e aos favores oficiais concedidos aos inacianos. Mas, a partir da expulsão da Companhia, pela primeira vez, reconhecia-se de maneira inequívoca a educação como dever do Estado.

Neste sentido, optei por dar tratamento ao problema como um processo de origem da educação "estatal" na América portuguesa. A expressão "estatal", tomei-a emprestada de Lorenzo Luzuriaga para caracterizar o novo processo político educacional em voga a partir da edição do Diretório de 1757, por Francisco Xavier de Mendonça Furtado. Diz o citado historiador que

"o movimento de secularização do ensino, começado nos séculos anteriores [ao século XVIII], cresce de ponto com a progressiva intervenção do Estado na educação, até vir a converter-se em função essencial do Estado, ocasionando aquilo que chamamos de educação pública estatal, isto é, educação subordinada aos fins do Estado." (LUZURIAGA, 1981, p.151). 


\section{Considerações Finais}

Nem sempre o que é propugnado em um determinado momento da história é realizável neste mesmo momento ou nos períodos que lhe seguem. Tomo como exemplo as obras dos grandes pensadores iluministas que tinham como objeto primordial a transformação das mentalidades, no sentido de tornar o homem capaz de se guiar pela própria razão, tornando-se autônomo e independente de qualquer autoridade exterior. Tal ideal vem a consubstanciar-se como concretude e ação cotidiana apenas alguns séculos depois. Isto, no entanto, não diminui a importância e o caráter essencialmente inovador das obras dos seus mais ilustres defensores.

Bárbara Freitag (1986, p.59) há muito já nos alertava a respeito de um time lag entre a promulgação e a efetivação de uma lei. Diz ela:

Se a lei é expressão dos interesses de uma classe ou coalizão de classes, esses interesses, materializados nos objetivos e fins de ensino só podem ser analisados na realidade e avaliados de acordo com o seu maior ou menor desvio das atenções originais, vários anos depois.

É dentro desta linha conceptiva que concebo o Diretório de 1757. Muito embora seus objetivos não tenham sido alcançados e, com efeito, sua edição tenha resultado em um relativo fracasso, as reflexões que continha e as propostas que lançava, caracterizavam-no francamente como um marco no processo de assunção por parte do Estado português, da responsabilidade em relação à educação, definindo uma nova relação deste com o problema da instrução dos índios e, posteriormente, de toda a colônia.

As escolas então criadas, o foram por iniciativa do Estado. Elas se constituem numa imposição estatal, fruto de sua necessidade, de um projeto político de colonização, por conseguinte, de aculturação. É aqui que Portugal antecede França, mas de um modo particular. Não é a República que descobre o valor da escola para a formação de uma nova cidadania, mas a Monarquia que revela sua face Absoluta.

Furtado não era somente um governador senão também, o coordenador da comissão de demarcação das terras de Portugal na Amazônia colonial, em conflito latente com a Espanha. Cabia basicamente a ele garantir que importantes nacos da possessão lusa na América não escorregassem para o domínio espanhol. Por isso

é preciso assinalar que todo documento jurídico que no período colonial
se relacionava com os índios do Brasil tem aspecto de lei geral. Esta
observação é especialmente apropriada à compreensão do Diretório, pois
sua aplicação aos índios do Brasil tinha, além de um propósito
evangelizador, o objetivo de solucionar grandes problemas da defesa
territorial e do povoamento, apresentando como sugestão um plano de
secularização no serviço da administração dos índios, o qual, entre outras
medidas, visava à substituição dos missionários regulares por
funcionários civis e militares. (ALMEIDA, 1997, p.14).

O acúmulo de funções não era coincidência. À missão de governar o grande Estado imbricava-se inseparável a de demarcar suas fronteiras com terras da Espanha e a estas duas, aliava-se a de garantir ocupação portuguesa nos espaços disputados e conquistados. $\mathrm{Na}$ ausência de portugueses em quantidade suficiente para efetivar tal ocupação, valeu-se Mendonça Furtado dos nativos amazônidas, estes, experientes no trato com a terra e com 
seus vizinhos. Entretanto, uma característica tinha de ser inoculada nestes indivíduos para que eles cumprissem bem a função de "portugueses": saber falar a "Língua do Príncipe".

Daí, a estreita ligação entre a expansão portuguesa no vale amazônico, corolário da política pombalina de exploração de matérias-primas e incentivo ao comércio na região, e as iniciativas de um ensino pretensamente sistemático e intensivo da língua portuguesa no Estado do Grão-Pará.

Saviani caracteriza muito bem esta perspectiva argumentando que

[...] o que caracteriza o modelo da Ilustração é seu espírito modernizador: secularização da vida em geral, com suas consequências sobre a sociedade e a administração, diversificação produtiva, atualização cultural e educativa, embora a preocupação estivesse limitada sobretudo ao propósito de instruir uma classe dirigente ampliada em seu número pela incorporação de novos setores e, de certo modo, também modificada qualitativamente. (SAVIANI, 1996, p.28-29).

Este não era o projeto dos Jesuítas, empenhados que estavam em difundir e implantar uma igreja supranacional através da constituição de missões sob sua jurisdição. Daí o violento conflito, cujo vitorioso - mesmo que parcial - foi Sebastião de Carvalho e Melo.

Em relação ao conflito entre a Coroa portuguesa - representada no Grão-Pará e Maranhão pelo seu governador - e os Jesuítas, pode-se arrolar várias causas. Entretanto, uma divergência de fundo salta aos olhos quando se investiga de forma mais acurada os interesses econômicos em jogo naquele tempo e espaço: o domínio da mão-de-obra. Tanto o próprio Mendonça Furtado, quanto os jesuítas José Caeiro e Antonio Vieira protagonista privilegiado (e insuspeito) no século anterior - são unânimes em confirmar esta tese.

Do ponto de vista político, os jesuítas possuíam além do poder espiritual, o poder temporal (governo) das aldeias; na economia, possuíam empreendimentos prósperos baseados na extração de matéria-prima e comércio, pecuária e engenhos; ideologicamente obtinham a confiança dos nativos graças a seu competente trabalho de catequese, além de dominar a "língua geral" (nheengatu), o que lhes garantia excelente fluxo de comunicação e informações. Um dos instrumentos mais eficazes de sua ação era, portanto, a escola onde curumins, filhos dos principais ${ }^{6}$ e mesmo de colonos, todos juntos, aprendiam como deveria ser a vida do bom cristão.

Todo esse "paraíso" desmorona com a intervenção direta do governo Mendonça Furtado, sobretudo com a edição do Diretório de 1757. A partir de então, os religiosos passam a exercer apenas o poder espiritual, pois o governo das aldeias, mais tarde elevadas à categoria de "lugares" ou "vilas", passam às mãos de um Diretor indicado pelo governo. Em termos de economia, o Estado pugna pelo estímulo à agricultura e ao comércio, que atinge seu ponto máximo com a criação da Companhia Geral em 1755. No plano ideológico e dos costumes, o documento estimula casamentos interétnicos, premia os que falam o português, cria escolas independentes das jesuítas e nomeia as aldeias com nomes de cidades portuguesas, transformando a face do Estado português na Amazônia.

Se o sistema diretoriano de escolarização não passou de um arremedo do monumental modelo jesuítico, seu projeto de implantação do uso da "Língua do Príncipe" obteve pleno êxito, integrando de uma vez por todas o imenso território amazônico à Pax portuguesa.

Como é possível perceber, a abordagem deste assunto tão pouco desenvolvido nos livros de História da Educação Brasileira é importante e decisiva para a compreensão da reforma pombalina dos estudos menores; de outro lado, é bastante preocupante a total 
ausência de referências a respeito do papel que Mendonça Furtado teve na elaboração de um projeto político e educacional profundamente inovador para os padrões da época e da importância do Estado do Grão-Pará como cenário deste movimento.

É evidente que os propósitos do governador, longe de serem altruístas, mais do que pelo intuito da socialização do saber, orientavam-se pelo objetivo de fortalecer a presença colonialista do Estado português na região, enfraquecendo resistências de toda ordem, sobretudo as culturais.

\section{REFERÊNCIAS}

ALMEIDA, Rita Heloísa de. O Diretório dos índios: um projeto de civilização no Brasil do século XVIII. Brasília: Ed. Universidade de Brasília, 1997.

ANDRADE, António Alberto Banha de. A reforma pombalina dos estudos secundários no Brasil. São Paulo: EDUSP/Saraiva, 1978.

António Alberto Banha de. Contributos para a história da mentalidade pedagógica portuguesa. Lisboa: Imprensa Nacional - Casa da Moeda, 1982.

AVELLAR, Hélio de Alcântara. História administrativa e econômica do Brasil. Rio de Janeiro: FENAME, 1970.

, Hélio de Alcântara. História administrativa do Brasil; a administração pombalina. Vol. 5. 2ª ed. Brasília: FUNCEP/ Ed. UNB, 1983.

AZEVEDO, Fernando de. A cultura brasileira. 6 ed. Rio de Janeiro: Ed. UFRJ/ Brasília: Ed. UNB, 1996.

AZEVEDO, João Lúcio d'. Estudos de história paraense. Belém: SECULT, 1994 [1893] (Série Lendo o Pará, vol. 19).

BRETAS, Genesco ferreira. História da instrução pública em Goiás. Goiânia: Editora UFG, 1991.

CARVALHO, Laerte Ramos de. A educação e seus métodos. In: HOLANDA, Sérgio Buarque de. (dir.). História geral da civilização brasileira, tomo I, $2^{\circ}$ vol. ( A época colonial ) 6a ed.. São Paulo: DIFEL, 1985.

Laerte Ramos de. As reformas pombalinas da instrução pública. São Paulo, Saraiva / EDUSP, 1978.

CARVAlHO, Rómulo. História do ensino em Portugal. Lisboa: Fundação Calouste Gulbenkian, 1986.

CASALI, Alípio. Elite intelectual e restauração da igreja. Petrópolis: Vozes, 1995.

CHARTIER, Roger (org.). História da vida privada, 3: da Renascença ao Século das Luzes. São Paulo: Companhia das Letras, 1991. 
CRUZ, Ernesto H. da. O Pará nos séculos XVII e XVIII (007-062). In: Anais do IX congresso de história nacional, $3^{\circ}$ vol. Rio de Janeiro: Instituto histórico e Geográfico brasileiro, 1950. . Colonização do Pará: Belém: CNPq, 1958. 1963.

História do Pará. 2 vol. Belém: UFPA, Coleção Amazônia. Série José Veríssimo,

CRUZ, Guilherme Braga de. Direitos e deveres do Estado na educação. (separata do IV Curso das Semanas Sociais Portuguesas, Braga, 1952). Lisboa: tip. União Gráfica, 1952.

DAMASCENO, Alberto e BARROSO, Wilson. Canhões, terços e letras: poder e educação no Grão-Pará. In: Para uma história da educação colonial. Lisboa: Sociedade Portuguesa de Ciências da Educação/Fundação Calouste Gulbenkian, 1996.

DUARTE, Sérgio Guerra. Dicionário Brasileiro de educação. Rio de Janeiro: Antares/Nobel, 1986.

FIALHO, Branca. A educação secundária no Brasil. Separata dos "Anais" do Terceiro Congresso de História Nacional (V volume). Rio de janeiro: Instituto Histórico/ Imprensa nacional, 1942.

FILHO, Bento de Andrade. História da educação. São Paulo: Livraria Acadêmica Saraiva \& Cia., 1941.

FREIRE, Ana Maria Araújo. Analfabetismo no Brasil. São Paulo: Cortez/Brasília: INEP, 1989.

FREITAG, Bárbara. Escola, Estado e sociedade. São Paulo: Moraes. $6^{\text {a }}$ ed. 1986.

GRAMSCI, Antonio. Concepção Dialética da História. 7 Ed: Rio de Janeiro, civilização Brasileira, 1987.

HUGON, Paul. História das doutrinas econômicas. 14 ed. São Paulo: Atlas, 1980.

LIMA, Lauro de Oliveira. Estórias da educação no Brasil: de Pombal a Passarinho. $3^{\mathrm{a}}$ ed. Rio de Janeiro: Ed. Brasília, s.d.

LINS, Ana Maria Moura. A burguesia em disfarce: a defesa da ignorância versus as lições do capital. Tese (Doutorado) Campinas: UNICAMP, 1992.

LOPES, Teixeira Marta Eliane. Perspectivas Históricas da Educação. $2^{\mathrm{a}}$ ed.. São Paulo: Ática, 1989.

LUZURIAGA, Lorenzo. História da educação e da pedagogia. $13^{a}$ ed.. São Paulo: Cia Ed. Nacional, 1981. 
MAXWELL, Kenneth. Marquês de Pombal: paradoxo do iluminismo. Rio de Janeiro, 1996.

MENDONÇA, Marcos Carneiro de. O pensamento da metrópole portuguêsa em relação ao Brasil. Separata da revista do Instituto Histórico e Geográfico Brasileiro. Vol. 257 - outubro/dezembro - 1962. Rio de Janeiro: IHGB, 1963.

MUNIZ, João de Palma. [Pará] A instrução pública (138-147). In: Dicionário Histórico Geográfico e Etnográfico do Brasil, vol.2. Rio de Janeiro: Instituto Histórico e Geográfico Brasileiro, 1922.

NAGLE, Jorge. História da educação brasileira: problemas atuais. In: EM ABERTO, Brasília, Ano 3, n. 23, set/out. 1984.

NUNES, Clarice. Guia preliminar de fontes para a história da educação brasileira. Brasília: INEP, 1992.

PAIVA, Vanilda. Educação popular e educação de adultos. São Paulo: Loyola, 1987.

PALACÍN, Luis. Subversão e corrupção: um estudo da administração pombalina em Goiás. Goiânia: Ed. UFG, 1983.

RIBEIRO, Maria Luisa. Introdução à História da Educação Brasileira. São Paulo: Cortez e Moraes, 1978.

SALLES, Vicente. O negro no Pará: sob o regime da escravidão. $2^{a}$ ed.. Brasília: MEC/Belém: SECULT/PA, 1988.

, Vicente. Épocas do teatro no Grão-Pará: ou, apresentação do teatro de época. Belém: UFPA, 1994.

SANTOS, Theobaldo Miranda. Noções de história da educação. $4^{a}$ ed. São Paulo: Cia. Editora Nacional, 1952.

SAVIANI, Dermeval (org.). Para uma história da educação latino-americana. Campinas: Autores Associados, 1996. (Coleção Polêmicas do Nosso Tempo).

SILVA, Garcilenil do Lago. Educação na Amazônia colonial: contribuição à história da educação brasileira. (Dissertação de Mestrado). Rio de Janeiro: PUC, 1976. (mimeo).

SILVA, Sulamita Castro Azevedo e. A Reforma Pombalina e a tecnologia educacional. Dissertação (Mestrado) Rio de Janeiro: UERJ, 1989.

SIMONSEN, Roberto C. História econômica do Brasil (1500 - 1820). $5^{\text {a }}$ ed.. São Paulo: Cia. Editora Nacional, 1967.

SOUZA, Laura de Mello e (org.). História da vida privada no Brasil: cotidiano e vida privada na América portuguesa. São Paulo: Companhia das Letras, 1997-A. 


\author{
VIANA, Hélio. A educação no Brasil colonial. In: Revista Brasileira de Estudos \\ Pedagógicos. vol. VI, n 18,1945 , pp. 372-392.
}

\author{
WARDE, Miriam J. Anotações para uma historiografia da educação brasileira. In: EM \\ ABERTO, Brasília, Ano 3, n. 23, set/out. 1984.
}

\title{
Notas
}

1 Professor da Universidade Federal do Pará - UFPA

2 Livros sobre história geral da educação: Bento de Andrade Filho na sua "História da educação" reserva um apêndice para "A educação na América e no Brasil” e vaticina à página 269: "educacionalmente, o Brasil não tem, de fato, história"; Francisco Larroyo em obra intitulada "História Geral da Pedagogia" também dedica um apêndice à história da educação no Brasil, em que trata do período pombalino; da mesma forma, Thomas Ransom Giles no seu livro "História da Educação" menciona o tema em quatro parágrafos no último capítulo de seu trabalho; Nelson e Claudino Piletti no livro denominado "História da Educação" abordam o assunto em um item do capítulo dedicado aos Jesuítas; Maria Lúcia de Arruda Aranha na sua "História da educação", parte II do capítulo 9, discute "o Brasil na era pombalina" em dois itens: "a expulsão dos jesuítas"e "a reforma pombalina".

Livros sobre a história da educação no Brasil: Na introdução de sua obra dedicada ao Conde D'Eu, denominada "História da instrução pública no Brasil", José Ricardo Pires de Almeida trata do período pombalino reproduzindo inclusive o Alvará de 1759. Branca Fialho em trabalho sobre "A educação secundária no Brasil" encerra a primeira parte do mesmo fazendo uma única e sucinta menção à ação pombalina: "houve uma grande modificação da instrução no Brasil com o Marquês de Pombal", todavia, o período que inicia em 1759 ela denomina "Expulsão dos jesuítas". Leonardo Trevisan destaca a fase pombalina com bastante ênfase no segundo capítulo de seu livro "Estado e educação na história brasileira"; Maria Luisa Santos Ribeiro na sua "História da educação brasileira", dedica uma parte do $1^{\circ}$ capítulo a esse estudo, denominando-o "A fase pombalina da escolarização colonial”; Theobaldo Miranda Santos no livro "Noções de história da educação" aborda suscintamente o tema em um apêndice de sua obra dedicado à educação brasileira; Ana Maria Araújo Freire em "Analfabetismo no Brasil” também dedica uma parte de seu trabalho ao que ela chama de "Período pombalino ou da remodelação iluminista"; Luiz Antônio Cunha desenvolve bom estudo sobre "O período pombalino" em seu trabalho "A universidade temporã"; Vanilda Paiva (1983) aborda rapidamente no item "A educação popular na colônia" de seu livro "Educação popular e educação de adultos", a expulsão dos Jesuítas e a criação das aulas régias; na cronologia histórica da educação no Brasil do seu "Dicionário brasileiro de educação", Sérgio Guerra Duarte ressalta alguns anos relativos ao período de Pombal; outro livro, que não é de história da educação, mas refere-se diretamente à questão é o $2^{\circ}$ volume do tomo I da "História geral da civilização brasileira" (a época colonial administração, economia, sociedade) organizado por Sérgio Buarque de Holanda, nele Laerte Ramos de Carvalho escreve como colaborador o capítulo II do livro segundo, "A educação e seus métodos", onde aborda as reformas pombalinas. No $4^{\circ}$ capítulo do seu livro "Educação e dependência" Manfredo Berger ensaia uma periodização do sistema educacional brasileiro e conclui que o período pombalino representou um ensaio de secularização influenciado pelo iluminismo europeu. Diz o autor, que após a expulsão dos jesuítas das colônias ultramarinas portuguesas não houve reforma, mas paralisações das atividades educacionais, pois foram fundadas "escolas e aulas régias" (latim, grego e retórica) insignificantes em número, qualidade e resultados, com professores inaptos, currículo irregular e lições de disciplinas avulsas, havendo, entretanto, interesse da metrópole em ter um sistema educacional eficiente na colônia. Em sua grande obra "A cultura brasileira" (parte terceira, capítulo I), Fernando de Azevedo confirma a expulsão dos jesuítas como "uma organização escolar que se extinguiu sem que essa destrição fosse acompanhada de medidas imediatas,..." (p.524). Lauro de Oliveira Lima, em suas "Estórias da educação no Brasil: de Pombal a Passarinho" diz que "a iniciativa de Pombal era, paradoxalmente 'esclarecida' na medida em que abolia o monopólio educacional de uma 'companhia' [de Jesus]...", e continua afirmando que "Pombal eliminou esta alternativa durante um século e meio; nem órgão público, nem 'companhia' leiga ou religiosa cuidaria durante este espaço de tempo da educação nacional”. Hyrla Aparecida Tucci Leal elaborou uma dissertação de mestrado defendida na PUC/SP, denominada "A evolução da educação humanista no Brasil, da Colônia à $1^{a}$ República: uma abordagem histórico-filosófica", cujo capítulo segundo analisa as reformas de Pombal nos marcos da "educação humanista no Brasil Colônia e sua manifestação no Império". Ali também corrobora a tese de que nada houve além da substituição do sistema jesuítico pelas aulas régias. No capítulo $4^{\circ}$ 
denominado "Evolução da administração escolar no Brasil", pertencente ao livro "Administração Escolar", Arnaldo Niskier afirma que após a expulsão da Companhia Pombal "tentou suprir a falta dos jesuítas com a criação de um primeiro sistema de ensino estatal: as classes ou aulas régias” (grifo do autor). Maria Elizabete Xavier, Maria Luisa Ribeiro e Olinda Maria Noronha, no seu livro "História da educação: a escola no Brasil", afirmam a reforma pombalina como "a supressão pura e simples do sistema que havia"; para as autoras, naquele período não houve "nenhuma reforma cultural, nenhuma reforma educacional;...". Em obra mais recente ("Elite intelectual e restauração da igreja"), Alípio Casali dedica um ítem do $2^{\circ}$ capítulo ("A era de Pombal: secularização para inglês ver) ao tema em estudo.

Livros sobre a história da educação em regiões ou Estados brasileiros: Em "História da educação em Sergipe", Maria Thetis Nunes (1992) inicia seu primeiro capítulo tratando do Alvará que expulsou os Jesuítas e desenvolve breve análise das diretrizes então adotadas; Genesco Ferreira Bretas na sua "História da instrução pública em Goiás" dedica longas notas ao estudo do período como um todo, muito embora a primeira escola pública em Goiás tenha sido criada, segundo o autor, somente em 1787; no "Diccionario Historico, Geographico e Ethnographico do Brasil” (Introducção Geral, Segundo Volume - Estados), publicação do Instituto Histórico e Geográfico Brasileiro, Palma Muniz desenvolve o que vem a ser o ensaio mais completo - embora ainda bastante insuficiente - sobre a história da educação no Pará. No capítulo XI da obra citada, trata o estudioso da "Instrucção Publica" no Pará, dividindo sua evolução em quatro fases distintas. A primeira, de 1616 a 1799, ele denomina de "período colonial primário" e caracteriza-a como um: periodo embryonario, desprovidos [sic] de methodos geraes approvados préviamente e de programmas officiaes, e falho completamente de estatísticas. (MUNIZ, 1922, p.138). Em sua dissertação de mestrado "Educação na Amazônia colonial: contribuição à história da educação brasileira" Garcilenil do Lago Silva analisa as ações pombalinas na Amazônia, a partir do Diretório de Mendonça Furtado. Em seu trabalho, o mais completo em termos de educação colonial na Amazônia, o Diretório de 1757 já é tratado com o necessário destaque.

Em sua "História econômica do Brasil" o professor Roberto Simonsen concorda com o papel pioneiro de Pombal no que tange à descoberta econômica da Amazônia: É inegável a especial atenção que de Pombal mereceu essa grande região sul-americana. Para o seu programa de expansão econômica de Portugal, depositava o Ministro grande confiança nos recursos e no comércio dessa zona, emprestava valor exagerado à riqueza das Missões e acreditava que as dezenas de milhares de indígenas, em trabalho livre, produziriam muito mais do que no regime existente. (SIMONSEN, 1967, p. 333).

${ }^{4}$ Dados a respeito do governador do Grão-Pará, podem ser conseguidos no excelente estudo de João Lúcio d'Azevedo, denominado “A Companhia de Commercio do Gram-Pará e o Marquez de Pombal” no livro do mesmo autor, constante da bibliografia deste trabalho. Azevedo atribui a Mendonça Furtado uma importância maior do que a que comumente observa-se em outros livros. Caracterizando-o como um dos oráculos de seu meio-irmão Carvalho e Melo, afirma que o mesmo foi "mal julgado pela história, que pouco tem dito de seus méritos" (AZEVEDO, 1994, p.13).

${ }^{5}$ Hélio Viana em “A educação no Brasil colonial”, in: "Revista Brasileira de Estudos Pedagógicos", n 18 , dezembro de 1945, tratando da instrução no século XVI argumenta que os jesuítas do Brasil haviam obtido do monarca os mesmos favores outorgados aos da India, havendo cada um, para manter-se, ferramentas (um cruzado em ferro), 5\$600 anuais para vestuário (quantia insuficiente, para Nóbrega) pagando-se em 1550-51, a Nóbrega, $2 \$ 400$ mensais para manutenção de seis jesuítas, tendo aumentado sempre os subsídios oficiais (um alvará de 1557 abonou a cada um dos vinte e oito inacianos então presentes no Brasil quatro "panicus" de mandioca, um alqueire de arroz ou milho e um cruzado em dinheiro; Men de Sá, em 1559, elevou as dotações individuais de 5 mil réis anuais e 12 cruzados em ferro; o alvará de 7 de novembro de 1566 atribuiu aos inacianos a décima de todos os dízimos - redízima que, só na Bahia, conferia 20 mil réis a cada um dos sessenta padres, anualmente, isto é, 3 mil cruzados totais. Em janeiro de 1576, o poder público atendeu o pedido, feito pêlos padres, de 2 mil e duzentos cruzados de mantimento e quinhentos cruzados para a fábrica dos colégios; contemporaneamente à "Narrativa Epistolar" de Fernão Cardim (1584), o colégio do Rio de Janeiro recebia dos cofres públicos 2 mil cruzados).(VIANA, 1945, p.374-575).

${ }^{6}$ Apesar de ser um termo geralmente utilizado para designar os chefes das tribos contactadas, há estudos evidenciando que na maioria das vezes os "principais" não são líderes dos índios descidos, mas pessoas com trânsito entre os colonos brancos e autoridades do governo colonial. Liderança fundada no domínio da língua portuguesa e da "língua geral" e no tino comercial para essa atividade. (ALMEIDA, 1997, p.327).

Recebido em abril-2014

Aprovado em maio-2014 